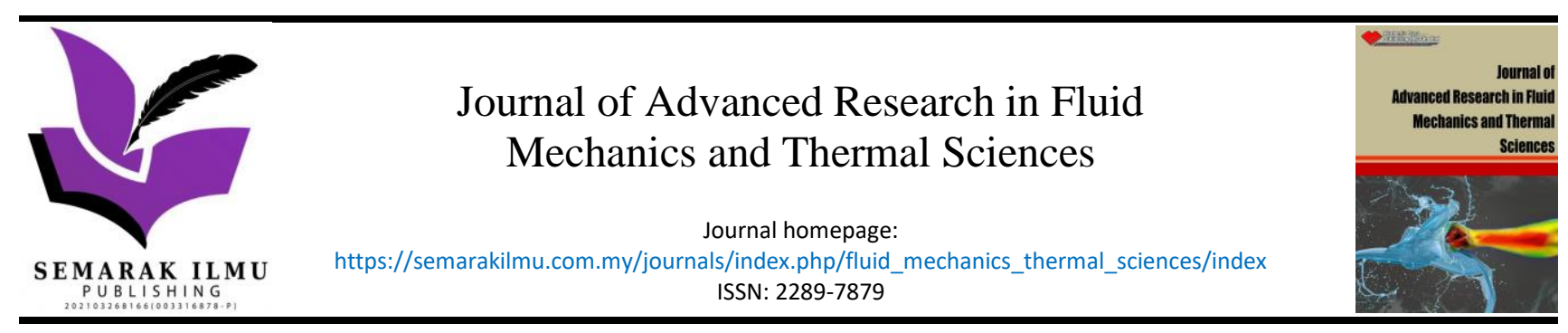

\title{
Numerical Simulation of Steady and Unsteady Flow and Entropy Generation by Nanofluid Within a Sinusoidal Channel
}

\author{
Ehsan Kianpour ${ }^{1,2,{ }^{*}}$, Nor Azwadi Che Sidik ${ }^{3}$, Seyyed Muhammad Hossein Razavi Dehkordi ${ }^{1,2}$, Siti \\ Nurul Akmal Yusof ${ }^{3,4}$ \\ Department of Mechanical Engineering, Najafabad Branch, Islamic Azad University, Najafabad, Iran \\ Aerospace and Energy Conversion Research Center, Najafabad Branch, Islamic Azad University, Najafabad, Iran \\ 3 Malaysia-Japan International Institute of Technology, Universiti Teknologi Malaysia, Jalan Sultan Yahya Petra, Kuala Lumpur, 54100, Malaysia \\ Fakulti Reka Bentuk Innovatif dan Teknologi, Universiti Sultan Zainal Abidin, Kampus Gong Badak, 21300 Terengganu, Malaysia
}

\section{ARTICLE INFO}

\section{Article history:}

Received 11 September 2021

Received in revised form 28 October 2021

Accepted 5 November 2021

Available online 29 November 2021

\section{Keywords:}

Nanofluid; Sinusoidal channel; Heat transfer; Entropy generation; Unsteady flow

\section{ABSTRACT}

Heat transfer has always been one of the most important aspects of human life. So far, many sources have been reported on methods of increasing the heat transfer rate. Many of these methods focus on changes in equipment structure. These techniques can hardly cope with the growing demand for heat transfer and compression in equipment. Recent advances in nanoparticle production can be seen as a breakthrough in methods of increasing heat transfer. The purpose of this study is to numerically investigate the flow field and heat transfer of water-aluminium oxide nanofluid in a wavy channel. The channel consists of two parallel plates and is divided into three parts in the longitudinal direction. The beginning and end parts of the channel are insulated and the middle part is sinusoidal and receives a uniform heat flux. The nanofluid enters the channel at a uniform speed and temperature and exits it in an expanded manner. For numerical analyses, the finite difference method based on control volume and simple algorithm is used. In this research, Reynold's effect was analysed. The results showed that by increasing the Reynolds number, the speed, temperature gradient and heat transfer rate was increased and the thickness of the thermal boundary layer was decreased. With increasing Reynolds number, the amount of heat transfer from the wall to the fluid and also the production of entropy increases. In the unsteady state, with increasing time and flow rate, the amount of heat transfer and total entropy and temperature gradient increase to reach the steady state.

\section{Introduction}

Heat transfer always is one of the most important and influential aspects of human life. Many researches have been done in this field for many years, most of which have been done with the aim of improving and accelerating heat transfer. Therefore, this science is still one of the most important fields of activity for researchers and scientists. Heat transfer has three specific mechanisms and the

\footnotetext{
* Corresponding author.

E-mail address: ekianpour@pmc.iaun.ac.ir
}

https://doi.org/10.37934/arfmts.89.2.2542 
most widely used heat transfer mechanism is convective heat transfer in which the presence of fluid plays an important role [1].

In the meantime, combined heat transfer is very common due to its simplicity, low volume, recovery and low cost. In such a way that its applications can be seen from the simplest of them in the daily life of human beings to the most complex industrial processes. This mechanism is even incorporated into the environmental sciences and is responsible for oceanic and atmospheric motion, as well as related heat transfer processes. So far, many sources have reported on methods of increasing the convective heat transfer coefficient $[2,3]$. Many of these methods focus on changes in equipment structure, such as increased thermal surfaces (blades), vibration of thermal surfaces, injection or suction of fluids, and application of electric or magnetic current. These methods can hardly meet the growing needs for heat transfer and compression equipment, including electronic chips, laser systems, and high-energy processes. Recent advances in nanoparticle production can be seen as a breakthrough in methods of increasing heat transfer.

Fluids such as air have very little cooling potential, which is not effective for cooling purposes such as the electronics industry, which aims to dissipate high heat fluxes $[4,5]$. The thermal conductivity of liquids is greater than that of gases, and the use of liquid fluids increases the heat transfer efficiency and cooling of the system. The use of solid particles in liquid has long been considered by humans. millimeter and micrometer dimensions, which resulted in problems such as suspension heterogeneity and deposition, and so on. With the advent of nanotechnology technology, nanoparticles have been used to suspend liquids, which in itself largely solves previous problems. These stable suspensions that improve the thermophysical properties of the fluid are called nanofluids. Alvarino et al., [6] numerically investigated a slow flow developed from water-alumina nanofluid in a tubular channel under a constant heat flux boundary condition, taking into account the effects of brownian and thermofertric diffusion. The volume percentage of nanoparticles in their study was up to $6 \%$. The results showed that a boundary layer developed along the tube, which is gradually depleted by nanoparticles. Also, the increase in heat transfer, especially in the high-volume percentages of nanoparticles, is small, so that the highest increase in heat transfer is about $5 \%$. Ajeel et al., studied the effects of turbulent forced convection of nanofluids flow in different configurations of trapezoidal corrugated channels over Reynolds number ranges of 10000 to 30000 [7]. Also, the effects of four different types of nanofluids which are $\mathrm{Al}_{2} \mathrm{O}_{3}, \mathrm{CuO}, \mathrm{SiO}_{2}$ and $\mathrm{ZnO}$-water under constant heat flux condition $(10 \mathrm{kw} / \mathrm{m} 2)$ were considered. For all studied forms, the nozzle rib configuration of trapezoidal corrugated channel achieved maximum PEC and can lead to more compact heat exchangers. Rush et al., [8] experimentally investigated local heat transfer and flow behavior in a sinusoidal corrugated channel. They found that the physical Reynolds number and how the sinusoidal wave is applied affect the rate of heat transfer.

Yang et al., [9] numerically studied the heat transfer and pressure drop in a corrugated channel with a sinusoidal wall. They found that heat transfer and loss coefficients increased with increasing amplitude of the wave surface. Azman et al., simulated a hybrid nanofluids flow in a straight pipe using Ansys Fluent software [11]. This study was carried out on $\mathrm{Al}_{2} \mathrm{O}_{3}+\mathrm{Cu} /$ water hybrid nanofluids to analyze the thermal improvement and friction factor of nanofluids occur in a straight pipe. The results showed that that the mono nanofluids at $1 \%$ and $4 \%$ indicate an increase in Nusselt number at $17 \%$ and $24 \%$ respectively and hybrid nanofluid increase at $2 \%$ to $5.6 \%$ compared to base fluid. Naphon [11] investigated heat transfer and pressure drop in a corrugated channel with a fixed flux wall. They found that heat transfer and pressure drop were directly related to the corrugated surface. Pahlivan et al., [12] investigated heat transfer in a sinusoidal channel with three different fin shapes. The results showed that increasing the corrugated angle increases the rate of heat transfer in the duct. Akbarzadeh et al., [13] numerically examined a corrugated channel and found that increasing the 
Reynolds number from 400 to 1400 increases the channel efficiency by $3.6 \%$. Muhammad et al., employed the single-phase numerical method to study the effects of different nanofluids on heat transfer and pressure drop penalty in the Diverging-converging mini channel heat sink $[14,15]$. The nanofluids are prepared as stable nanoparticles of $\mathrm{Al}_{2} \mathrm{O}_{3}, \mathrm{Cu}$, and $\mathrm{SiO}_{2}$ and suspended in deionized water with concentrations of $0-0.8 \%$ volume. The results showed that an insignificant change in pressure drops with a variation of nanofluids loadings, whereas, the increase in Reynolds number and nanoparticle loading indicated a considerable influence on the enhancement of heat transfer coefficient. Beng and Japar stimulate the nanofluids flow in straight channel and corrugated microchannel using ANSYS software [16]. In their study, hydraulic diameter was $133.3 \mu \mathrm{m}$, Knudsen Number was fixed when flow was considered continuum, Reynold number was set below than 1400, so that the flow in within laminar region, the inlet temperature fixed at $300 \mathrm{~K}$, uniform heat flux $100 \mathrm{~W} / \mathrm{cm}^{2}$ and inlet velocity in the range of $1.0 \mathrm{~m} / \mathrm{s}$ to $4.5 \mathrm{~m} / \mathrm{s}$. The results showed that triangular cavities that using high volume fraction of nanofluid has better performance compared to straight channel with the same volume fraction of nanofluid.

Xie et al., [17] optimized the corrugated channel and found that the corrugated channel structure has a high thermal efficiency at low Reynolds number. They examined the slow flow in a heatsink, which itself contained a two-layer channel, and found that the shape of the channel was very important to the heat transfer rate. Zhang et al., [18] proposed a new relation for the calculation of heat transfer and pressure drop in a corrugated channel. Ajeel et al., numerically investigated the effects of forced turbulent convective flow and heat transfer in a symmetric semicircle corrugated channel with SiO2-water nanofluid as the working fluid [19]. The results showed that the average Nusselt number enhances with increase in Reynolds number and with the height of the corrugated channel. Han et al., [20] numerically optimized the types of corrugated tubes. Do et al., [21] numerically optimized a finned heat exchanger and found that they could improve the heat transfer rate by $6.2 \%$ and the pressure drop by $40 \%$. Asadi et al., [22] numerically investigated a twodimensional corrugated channel in which a slow and forced flow of iron oxide and water nanofluid flowed. They studied the effect of magnetic field, Reynolds number, nanoparticle volume percentage and wave amplitude on heat transfer rate. Finally, they found that the increase of volume percentage of nanoparticles and the Reynolds number had a positive effect and an increase in the magnetic field had a negative effect on the heat transfer rate. Shahsavar et al., showed that the influence of Reynolds number on the Nusselt number is much higher than that of nanoparticle concentration [23]. The increasing of the Reynolds number and decreasing of nanoparticle concentration, results in increasing the Nusselt number for channels.

Based on the mentioned literature, most researches on the application of nanofluids in wavy channels have focused on the steady flow. In addition, a few researches have been carried out to utilize the entropy generation. Consequently, the aim of the present study is to improve the mixed convective heat transfer for nanofluid flow inside a wavy channel using the entropy generation. $\mathrm{Al}_{2} \mathrm{O}_{3}$-water nanofluid is chosen as working fluid due to its low cost and good heat transfer characteristic. The $\mathrm{Al}_{2} \mathrm{O}_{3}$ is a common material which could be prepared easily. As the first study on mixed convection nanofluid flow inside sinusoidal wavy channels, the effect of the nanoparticle volume fraction and geometry parameters are investigated on heat transfer characteristics and entropy generation. 


\section{Methodology}

Navier-Stokes equations are considered as governing equations of flow and by solving them, the flow is analyzed. It should be noted that these equations only govern the DC regime. However, in numerical simulation, not all physical conditions can be considered and a series of approximations are required. Therefore, numerical simulations should be validated by laboratory results and then used as a design criterion. The geometry considered in this research, according to Figure 1, is a twodimensional corrugated channel with a corrugated part with a constant temperature $T_{h}$ in the middle. At the beginning and end of the channel there is an initial and end length that are completely insulated. Also, alumina water nanofluid enters the channel with temperature $T_{c}$ and speed $u_{0}, v_{0}$ and leaves the channel after cooling with the condition of thermal and hydrodynamic expansion.
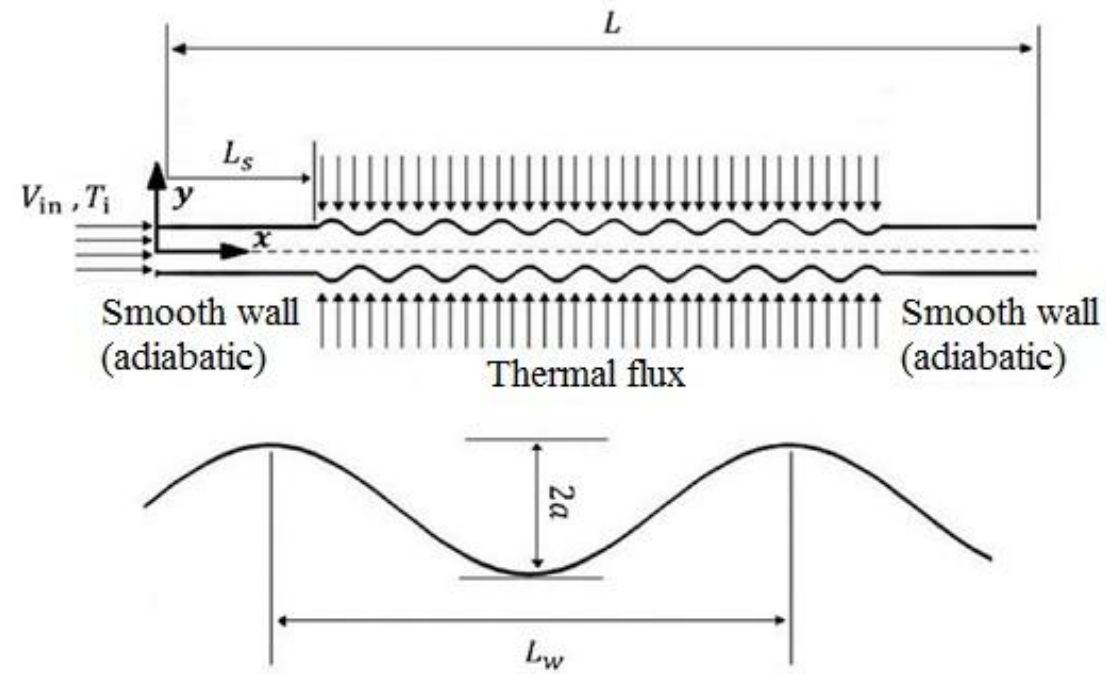

Fig. 1. Two-dimensional geometry of the research model

In this research, laminar and unsteady flow was assumed. The nanofluid is assumed to be a continuous medium with a thermal equilibrium between the base fluid and the solid particles. The governing two-dimensional equations for the two-dimensional smooth flow in the channel are assumed to be incompressible Newtonian fluid. Volumetric force, like gravity, is neglected. These equations according to the following hypotheses as follows [24, 25]:

i. The flow is laminar and steady and unsteady.

ii. Newtonian fluid.

iii. The flow has no volumetric force.

iv. The properties of nanofluids vary with temperature.

v. Conductive heat transfer follows the Fourier law.

vi. Ignore the effects of viscosity losses and the effects of radiation.

vii. Thermal balance of fluid and nanoparticles.

viii. Nanofluid is considered as single phase.

ix. Nanoparticles are uniform in shape and size

$\frac{\partial u}{\partial x}+\frac{\partial v}{\partial y}=0$ 


$$
\begin{aligned}
& \frac{\partial \mathrm{u}}{\partial \mathrm{t}}+\mathrm{u} \frac{\partial \mathrm{u}}{\partial \mathrm{x}}+\mathrm{v} \frac{\partial \mathrm{u}}{\partial \mathrm{y}}=-\frac{1}{\rho} \frac{\partial \mathrm{p}}{\partial \mathrm{x}}+\frac{1}{\rho_{n f}}\left(\frac{\partial}{\partial \mathrm{x}}\left(\mu_{n f} \frac{\partial \mathrm{u}}{\partial \mathrm{x}}\right)+\frac{\partial}{\partial \mathrm{y}}\left(\mu_{n f} \frac{\partial \mathrm{u}}{\partial \mathrm{y}}\right)\right) \\
& \frac{\partial \mathrm{v}}{\partial \mathrm{t}}+\mathrm{u} \frac{\partial \mathrm{v}}{\partial \mathrm{x}}+\mathrm{v} \frac{\partial \mathrm{v}}{\partial \mathrm{y}}=-\frac{1}{\rho_{n f}} \frac{\partial \bar{P}}{\partial \mathrm{y}}+\frac{1}{\rho_{n f}}\left(\frac{\partial}{\partial \mathrm{x}}\left(\mu_{n f} \frac{\partial \mathrm{v}}{\partial \mathrm{x}}\right)+\frac{\partial}{\partial \mathrm{y}}\left(\mu_{n f} \frac{\partial \mathrm{v}}{\partial \mathrm{y}}\right)\right) \\
& \left(\frac{\partial \mathrm{T}}{\partial \mathrm{t}}+\mathrm{u} \frac{\partial \mathrm{T}}{\partial \mathrm{x}}+\mathrm{v} \frac{\partial \mathrm{T}}{\partial \mathrm{y}}\right)=\frac{\mathrm{k}_{n f}}{\left(\rho C_{P}\right)_{n f}}\left(\frac{\partial^{2} \mathrm{~T}}{\partial \mathrm{x}^{2}}+\frac{\partial^{2} \mathrm{~T}}{\partial \mathrm{y}^{2}}\right) \\
& S_{g e n}=\frac{\mathrm{k}_{n f}}{T_{0}^{2}}\left(\left(\frac{\partial \mathrm{T}}{\partial \mathrm{x}}\right)^{2}+\left(\frac{\partial \mathrm{T}}{\partial \mathrm{y}}\right)^{2}\right)+\frac{\mu_{n f}}{T_{0}}\left\{2\left[\left(\frac{\partial \mathrm{u}}{\partial \mathrm{x}}\right)^{2}+\left(\frac{\partial \mathrm{v}}{\partial \mathrm{y}}\right)^{2}\right]+\left(\frac{\partial \mathrm{u}}{\partial \mathrm{y}}+\frac{\partial \mathrm{v}}{\partial \mathrm{x}}\right)^{2}\right\} \\
& \Psi(x, y)=\int u d y+\Psi_{0}
\end{aligned}
$$

In Eq. (1) to (6), using the dimensionless variables introduced in Eq. (7), the equations are rewritten dimensionless. The definition of dimensionless numbers Prantel ( $P r)$ and Reynolds $(\operatorname{Re})$ is also given in Eq. (7):

$$
\begin{aligned}
& \mathrm{X}=\frac{\mathrm{x}}{l}, \mathrm{Y}=\frac{\mathrm{y}}{l}, \mathrm{U}=\frac{\mathrm{u}}{\mathrm{u}_{0}}, \mathrm{~V}=\frac{\mathrm{v}}{\mathrm{v}_{0}}, \mathrm{P}=\frac{\overline{\mathrm{P}} l^{2}}{\rho_{\mathrm{nf}} \alpha_{\mathrm{f}}^{2}}, \Theta=\frac{T-T_{c}}{\Delta T}, \Delta T=\frac{\mathrm{q}_{0}^{\prime \prime} h}{k_{f}}, \operatorname{Pr}=\frac{\vartheta_{f}}{\alpha_{f}}, \operatorname{Re}= \\
& \frac{\rho u D}{\mu_{f}},
\end{aligned}
$$

By defining dimensionless quantities, dimensionless equations are obtained from Eq. (8) to (13), respectively:

$$
\begin{aligned}
& \frac{\partial \mathrm{U}}{\partial \mathrm{X}}+\frac{\partial \mathrm{V}}{\partial \mathrm{Y}}=0 \\
& \frac{\partial \mathrm{U}}{\partial \mathrm{t}}+\mathrm{U} \frac{\partial \mathrm{U}}{\partial \mathrm{X}}+\mathrm{V} \frac{\partial \mathrm{U}}{\partial \mathrm{Y}}=-\frac{\partial \mathrm{P}}{\partial \mathrm{X}}+\frac{\mu_{\mathrm{nf}}}{\rho_{\mathrm{nf}} \alpha_{\mathrm{f}}}\left(\frac{\partial^{2} \mathrm{U}}{\partial \mathrm{X}^{2}}+\frac{\partial^{2} \mathrm{U}}{\partial \mathrm{Y}^{2}}\right) \\
& \frac{\partial \mathrm{V}}{\partial \mathrm{t}}+\mathrm{U} \frac{\partial \mathrm{V}}{\partial \mathrm{X}}+\mathrm{V} \frac{\partial \mathrm{V}}{\partial \mathrm{Y}}=-\frac{\partial \mathrm{P}}{\partial \mathrm{Y}}+\frac{\mu_{\mathrm{nf}}}{\rho_{\mathrm{nf}} \alpha_{\mathrm{f}}}\left(\frac{\partial^{2} \mathrm{~V}}{\partial \mathrm{X}^{2}}+\frac{\partial^{2} \mathrm{~V}}{\partial \mathrm{Y}^{2}}\right) \\
& \left(\frac{\partial \theta}{\partial \mathrm{t}}+\mathrm{U} \frac{\partial \theta}{\partial \mathrm{X}}+\mathrm{V} \frac{\partial \theta}{\partial \mathrm{Y}}\right)=\frac{\alpha_{\mathrm{nf}}}{\alpha_{\mathrm{f}}}\left(\frac{\partial^{2} \theta}{\partial \mathrm{X}^{2}}+\frac{\partial^{2} \theta}{\partial \mathrm{Y}^{2}}\right) \\
& S_{g e n}=\frac{\mathrm{k}_{n f}}{\mathrm{k}_{f}}\left(\left(\frac{\partial \theta}{\partial \mathrm{X}}\right)^{2}+\left(\frac{\partial \theta}{\partial \mathrm{y}}\right)^{2}\right)+\zeta \frac{\mu_{n f}}{\mu_{f}}\left\{2\left[\left(\frac{\partial U}{\partial \mathrm{X}}\right)^{2}+\left(\frac{\partial \mathrm{V}}{\partial \mathrm{Y}}\right)^{2}\right]+\left(\frac{\partial \mathrm{U}}{\partial \mathrm{Y}}+\frac{\partial \mathrm{V}}{\partial \mathrm{X}}\right)^{2}\right\} \\
& \Psi(X, Y)=\int U d Y+\Psi_{0}
\end{aligned}
$$


In the entropy generation Eq. (12), the value of $\zeta$ is obtained as below:

$\zeta=\frac{\mu_{f} T_{0}}{\mathrm{k}_{f}}\left(\frac{\alpha_{\mathrm{f}}}{L\left(T_{h}-T_{C}\right)}\right)^{2}$

By integrating the whole area, the total entropy can be obtained

$$
S_{\text {Total }}=\int S_{g e n} d \Omega=\iint_{0}^{1} S_{g e n} d X d Y
$$

In the current study, researchers used a Simply Fortran v3.2.2976 to simulate the model. As it is clear from the governing equations, the thermophysical properties of nanofluids are needed to solve the equations. The electrical conductivity, density, volume expansion coefficient, heat capacity and nanofluid heat dissipation coefficient are calculated using the properties of fluid and nanoparticles from the following equations [26].

$$
\begin{aligned}
& \rho_{\mathrm{nf}}=(1-\varphi) \rho_{\mathrm{f}}+\varphi \rho_{\mathrm{p}} \\
& (\rho \beta)_{\mathrm{nf}}=(1-\varphi)(\rho \beta)_{\mathrm{f}}+\varphi(\rho \beta)_{\mathrm{p}} \\
& \left(\rho c_{\mathrm{p}}\right)_{\mathrm{nf}}=(1-\varphi)\left(\rho c_{\mathrm{p}}\right)_{\mathrm{f}}+\varphi\left(\rho c_{\mathrm{p}}\right)_{\mathrm{p}} \\
& \alpha_{\mathrm{nf}}=\frac{\mathrm{k}_{\mathrm{nf}}}{\left(\rho c_{\mathrm{p}}\right)_{\mathrm{nf}}}
\end{aligned}
$$

In these equations, subtitles $f$ and $p$ refer to the properties of water and $\mathrm{Al}_{2} \mathrm{O}_{3}$, respectively. These properties are listed in Table 1 . Also, $\mathrm{k}_{\mathrm{nf}}$ is the effective thermal conductivity of the nanofluid, which can be obtained from references [27-29] as below:

$\mathrm{k}_{\mathrm{nf}}=\mathrm{k}_{\text {Static }}+\mathrm{k}_{\text {Brownian }}=\left[\frac{\mathrm{k}_{\mathrm{p}}+2 k_{f}-2\left(\mathrm{k}_{\mathrm{f}}-\mathrm{k}_{\mathrm{p}}\right)}{\mathrm{k}_{\mathrm{p}}+2 k_{f}+\phi\left(\mathrm{k}_{\mathrm{f}}-\mathrm{k}_{\mathrm{p}}\right)}\right] \mathrm{k}_{\mathrm{f}}+\left[5 \times 10^{4} \beta \phi \rho_{\mathrm{f}} \mathrm{cp_{ \textrm {f } }} \sqrt{\frac{\mathrm{k}_{\mathrm{b}} \mathrm{T}}{\rho_{\mathrm{f}} \mathrm{d}_{\mathrm{p}}}} \mathrm{f}(\mathrm{T}, \phi)\right]$

In the above equation, $k_{p}$ is nanoparticle conductivity and $k_{f}$ is pure fluid conductivity. Boltzmann constant $k_{b}=1 / 3807 \times 10^{-23} 1 / K, T$ is the temperature of the nanofluid in terms of Kelvin and the combination of $\beta$ and $f(T, \varphi)$ for the nanofluid of water- $\mathrm{Al}_{2} \mathrm{O}_{3}$. The Brownian motion of nanoparticles in nanofluids is actually their random and continuous motion in the fluid. Liquid molecules constantly strike the nanoparticles and disperse them into the fluid. In the present study, the effect of this phenomenon on the thermal conductivity and viscosity of nanofluid was also considered.

$\mu_{\mathrm{nf}}=\mu_{\text {Static }}+\mu_{\text {Brownian }}=\frac{\mu_{\mathrm{f}}}{(1-\varphi)^{2.5}}+5 \times 10^{4} \beta \varphi \rho_{\mathrm{f}}\left(\mathrm{C}_{\mathrm{p}}\right)_{\mathrm{f}} \frac{\mu_{\mathrm{f}}}{\mathrm{k}_{\mathrm{f}} \operatorname{Pr}} \sqrt{\frac{\mathrm{k}_{\mathrm{b}} \mathrm{T}}{\rho_{\mathrm{p}} \mathrm{d}_{\mathrm{p}}}} \mathrm{f}(\mathrm{T}, \varphi)$

In Eq. (21), the terms $\beta$ and $f(T, \phi)$ are written as Eq. (20), (22) and (23) for the nanofluid water$\mathrm{Al}_{2} \mathrm{O}_{3}$ : 


$$
\begin{aligned}
& \mathrm{f}(\mathrm{T}, \varphi)=\left(2.8217 \times 10^{-2} \varphi+3.917 \times 10^{-3}\right)\left(\frac{\mathrm{T}}{\mathrm{T}_{0}}\right)+\left(-3.0669 \times 10^{-2} \varphi-3.91123 \times 10^{-3}\right) \\
& \beta=8.4407(100 \varphi)^{-1.07304}
\end{aligned}
$$

Table 1

Thermophysical properties of water- $\mathrm{Al}_{2} \mathrm{O}_{3}[30]$

\begin{tabular}{cll}
\hline Physical properties & water & nanoparticles $\mathrm{Al}_{2} \mathrm{O}_{3}$ \\
\hline$C_{P}(\mathrm{~J} / \mathrm{kg} \cdot \mathrm{k})$ & 4179 & 765 \\
$\rho\left(\mathrm{kg} / \mathrm{m}^{3}\right)$ & 1.997 & 3970 \\
$k(w / m . k)$ & 0.613 & 25 \\
$d_{P}(\mathrm{~nm})$ & - & 40 \\
\hline
\end{tabular}

To describe and draw flow lines, it is necessary to define the flow function. The flow function is a mathematical function that replaces the two components of velocity and is a relation between flow lines and the expression of mass stability. The flow function is defined as:

$\mathrm{U}=\frac{\partial \Psi}{\partial \mathrm{Y}}, \mathrm{V}=-\frac{\partial \Psi}{\partial \mathrm{X}}$

Equation 25 defines the local Nusselt number on a hot wall as well as the definition of the entropy parameter.

$N u=\frac{\lambda \mathrm{h}}{\mathrm{k}_{\mathrm{f}}}, \zeta=\frac{\mu_{n f} T_{0}}{k_{f}}\left(\frac{\alpha_{f}}{L\left(T_{h}-T_{C}\right)}\right)^{2}$

Calculating the heat exchange rate is one of the most important parameters. The total heat transfer rate is expressed in the form of a Nusselt number. The local Nusselt number of the lower and upper walls is defined according to Eq. (26):

$\mathrm{Nu}_{\mathrm{s}}=\frac{\lambda \mathrm{L}}{\mathrm{k}_{\mathrm{f}}}$

In the above relation $\mathrm{k}_{\mathrm{f}}$ is the thermal conductivity of pure fluid, $\mathrm{L}$ is the characteristic length and $\lambda$ is the convective heat transfer coefficient.

$\lambda=\frac{\mathrm{q}_{0}^{\prime \prime}}{\mathrm{T}_{\mathrm{s}}-\mathrm{T}_{\mathrm{c}}}$

The obtained equations can be used to calculate the temperature field and velocity components. For this purpose, the Simple algorithm is used. Also, for a better understanding of the simple algorithm, flowchart of this program is shown in Figure 2. 


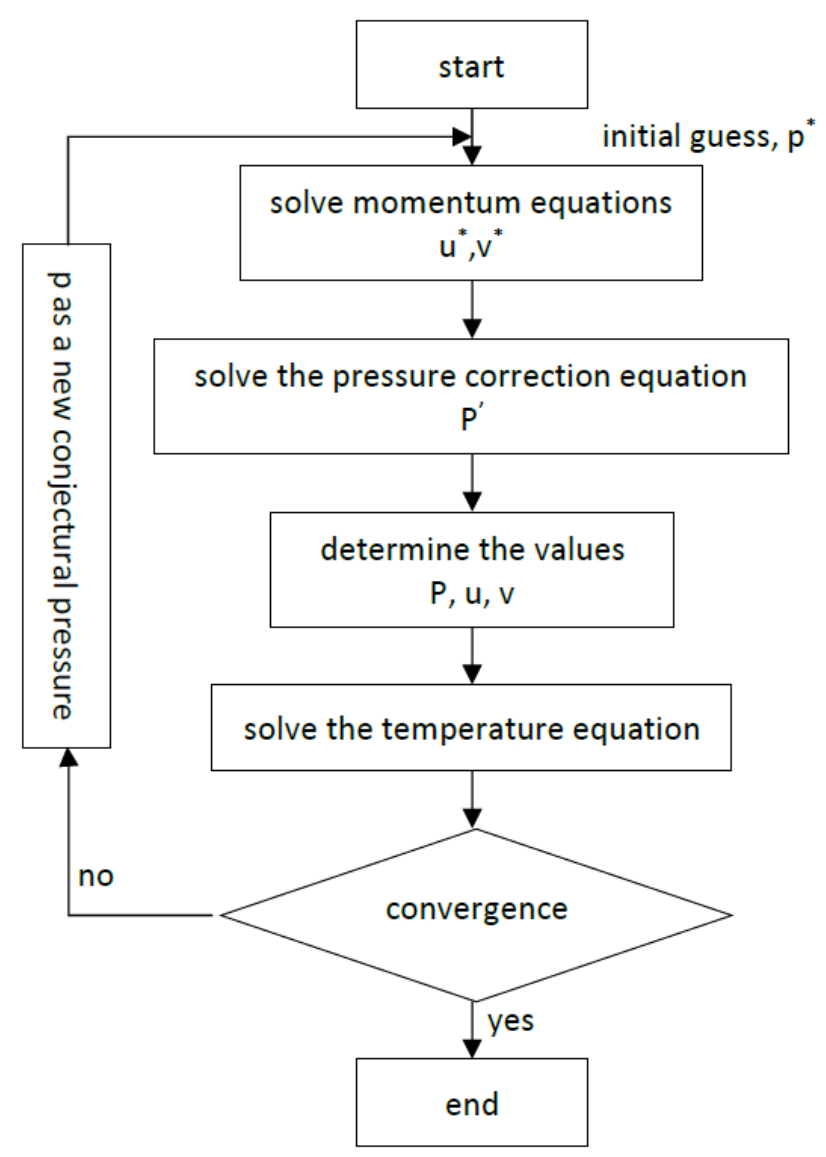

Fig. 2. Simple flowchart algorithm [31]

When executing the above algorithm, the isolated equations that are linearized must be solved. Because the problem is more than one dimension, it is not effective to use direct methods. For this purpose, the iteration method is used. In this method, it is necessary to solve the system of algebraic equations of $n$ equations and $n$ unknowns. Therefore, the line-by-line method is used to solve this system of equations. The line-by-line method is a combination of the TDMA matrix and Gauss-Sidel methods. The equations of the nodes on the line include the values of the points of the adjacent lines. If the values of adjacent points are subtracted from the previous values, the equations for the nodes on the principal line become one-dimensional and can be solved by the three-diagonal matrix method. This operation starts from one side and continues in the opposite direction. This method can be used for network lines along. Thus, the above algorithm is implemented in all parts of the network [32]. In general, the boundary conditions for solving equations are expressed as follows:

i. Speed limit conditions, including non-slip condition for all walls except corrugated: $\mathrm{U}=$ $V=0$

ii. Thermal boundary conditions for a corrugated part of a channel with a constant temperature $\left(T_{h}\right)$ or in other words $\theta=1$

iii. Temperature boundary conditions of the upper and lower walls of the channel with sinusoidal temperature profiles

iv. Boundary conditions for the channel output include thermal and hydrodynamic expansion $\theta=1,\left(\frac{\partial \mathrm{T}}{\partial \mathrm{x}}=0, \frac{\partial \mathrm{u}}{\partial \mathrm{x}}=0\right)$ 
The border conditions are as follows:
i. Wavy walls $\theta=1, V(X)=\mathrm{V}+\sin \left(\frac{2 \pi \mathrm{X}}{\mathrm{L}}\right)$
ii. Initial and end length of the channel $\theta=0, U=V=0$
iii. Channel input boundary condition $X=0, \mathrm{u}=\mathrm{u}_{0}, \mathrm{v}=\mathrm{v}_{0}, T=T_{c}$
iv. Channel output boundary condition $X=\mathrm{L}, \frac{\partial \mathrm{T}}{\partial \mathrm{x}}=0, \frac{\partial \mathrm{u}}{\partial \mathrm{x}}=0$

To select the appropriate solution network for the present geometry, the effect of the number of network points on the average Nusselt number was investigated. An example of the studies performed is given in Table 2. According to the table, it is clear that for networks smaller than $80 \times 800$, the answers remain the same and no significant change in values is seen. Therefore, the appropriate network for the implementation of the above program was selected as the network.

Table 2

Number of network points

\begin{tabular}{lcccccc}
\hline & $50 \times 500$ & $60 \times 600$ & $70 \times 700$ & $80 \times 800$ & $90 \times 900$ & $100 \times 1000$ \\
\hline $\mathrm{Re}=10$ & & & & & & \\
$N u_{\mathrm{m}}$ & 5.3303 & 5.3605 & 5.3834 & 5.4638 & 5.4703 & 5.4705 \\
$S_{\text {Total }}$ & 22.023 & 21.382 & 21.003 & 20.965 & 20.965 & 20.964 \\
$\mathrm{Re}=500$ & & & & & & \\
$N u_{\mathrm{m}}$ & 19.2615 & 19.4731 & 19.3713 & 19.8914 & 19.8914 & 19.8912 \\
$S_{\text {Total }}$ & 218.425 & 215.398 & 213.106 & 212.215 & 212.214 & 212.212 \\
\hline
\end{tabular}

\section{Results and Discussion}

To prove the effectiveness of the method, the numerical results were compared with similar studies findings conducted by various researchers. In this validation, the dimensions of the channel and the barrier as well as the boundary conditions of the flow were considered in accordance with Nor Azwadi et al., [33]. In this study, the forced convection of water-alumina nanofluid in a channel with five barriers was investigated by Lattice Boltzmann method. The barriers are located at the bottom of the channel, and the bottom wall and barriers were kept warm at a constant temperature and cooled by the cold inlet fluid. The upper wall of the channel is also insulated. According to Figure 3 , a very good agreement can be seen between the results. The deviations between the results of current research and benchmarks were computed by the following equation.

$\%$ Diff $=\frac{\sum_{i=1}^{n} \frac{\left(x_{i}-x_{i, \text { benchmark }}\right)}{x_{i, \text { benchmark }}}}{\mathrm{n}} \times 100$

In this research, the dimensionless length of the channel $\mathrm{L}=\mathrm{I} / \mathrm{H}=20$ is considered and, in its output, the boundary conditions of hydrodynamic and thermal development are used. Using this condition, the appropriate length of the channel is checked. For this purpose, for $\operatorname{Re}=10, \operatorname{Re}=500$ and $\phi=0.03$, with increasing the length of the end part, the average Nusselt number for different lengths of the channel was calculated. The results are presented in Figure 4. According to the figure, with increasing channel length, which is done by increasing the end length of the channel, the average Nusselt number and the horizontal velocity on the central axis of the channel have not changed after the length of 20 . Therefore, the length $L=20$ which was selected in this research is appropriate. 


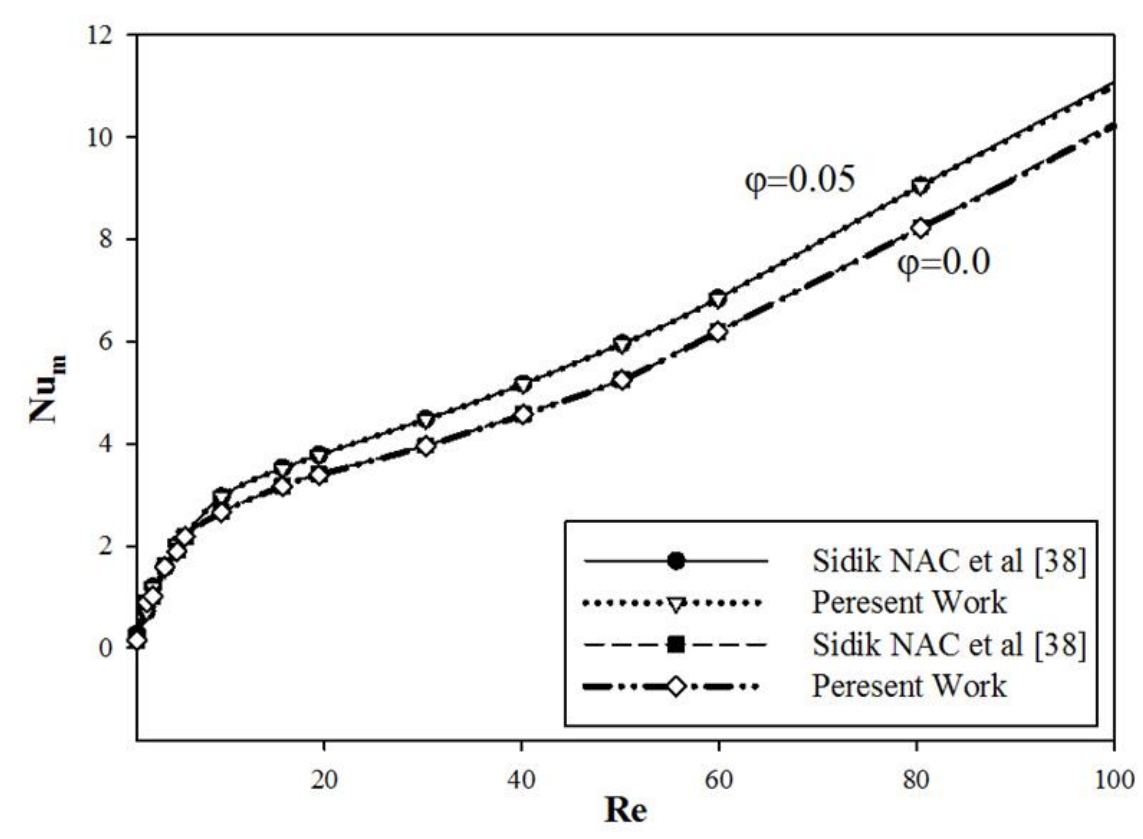

Fig. 3. Comparison of average Nusselt number per volume percentage and different Reynolds numbers between the current research results and Nor Azwadi et al., [33]

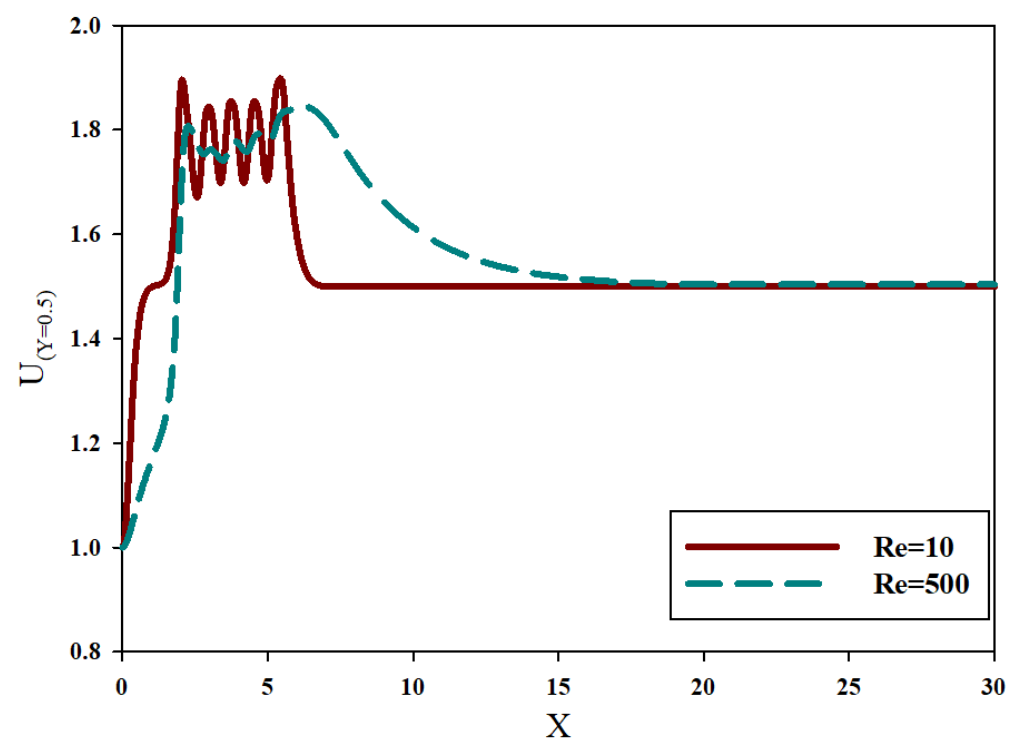

Fig. 4. Horizontal velocity on the central axis of the channel $(Y=0.5)$ for values of $\phi=0.03$ and different $R e=10, R e=500$ and different output lengths of the channel in the steady state

The effect of Reynolds number and forced convection on the flow and heat transfer field was investigated. According to Figure 5, flow lines are drawn for the values of $\phi=0.03$ and different Reynolds numbers. According to the figure, in order to better show the field of flow and temperature, it is not drawn for the whole channel and only the part of the channel where the wavy wall is located was displayed. With increasing Reynolds number, due to the increase of the effects of inertia and flow velocity, the vortices formed inside the channel indentation become stronger and the vortex inside the indentations increases with increasing Reynolds number. 


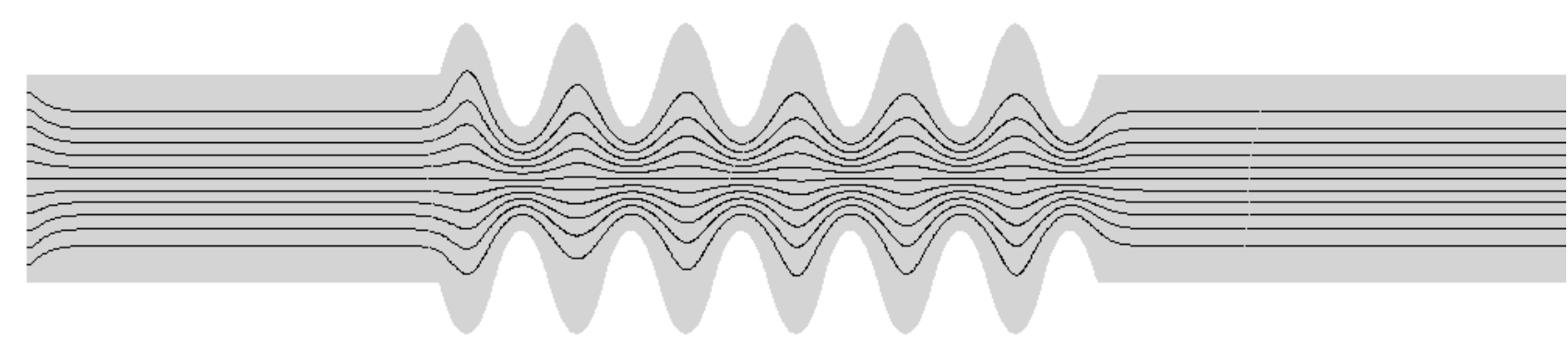

$\operatorname{Re}=10$

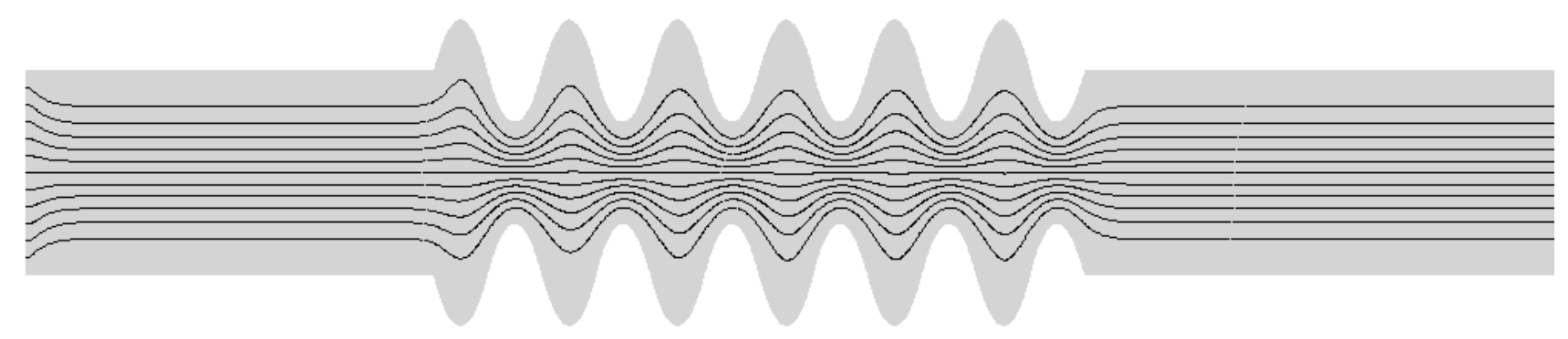

$\operatorname{Re}=20$

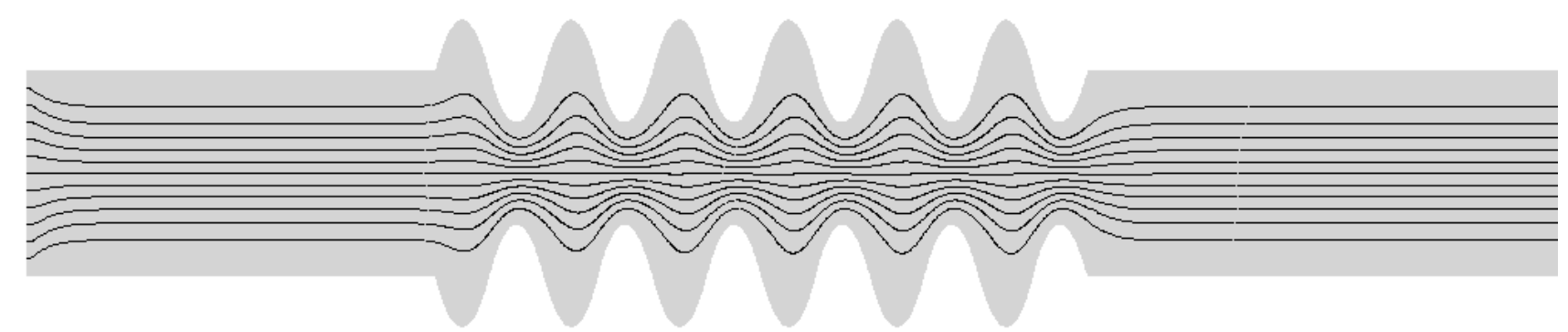

$\operatorname{Re}=100$

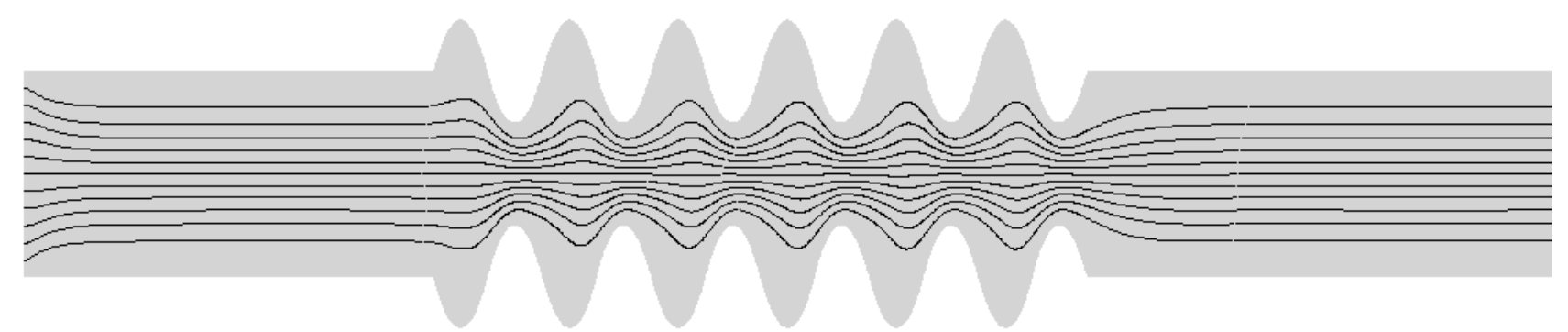

$\operatorname{Re}=200$

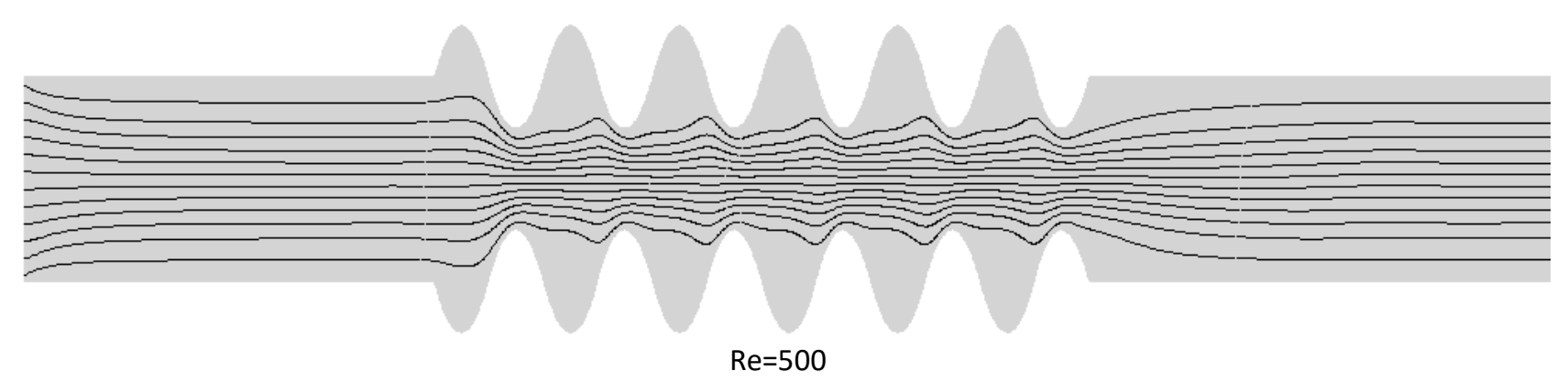

Fig. 5. Flow lines for values $\phi=0.03$ and different Reynolds numbers in the steady state

As shown in Figure 6, it can be seen that in the lower Reynolds lines, the isothermal lines are drawn towards the top of the lower wave wall and below the upper wave wall and the entire output section. As the Reynolds number increases, these lines are drawn and the temperature of the fluid in the center of the heat channel decreases. Due to the isothermal lines, with increasing Reynolds number due to increasing current inertia, the amount of heat transfer increases. This can be seen 
from the compaction of isothermal lines adjacent to the wavy walls. Also, in the indentations of waveshaped walls, with increasing Reynolds number due to increasing fluid inertia, the strength of vortices increases and the amount of heat transfer increases due to decreasing the thickness of the thermal boundary layer and increasing the temperature difference.

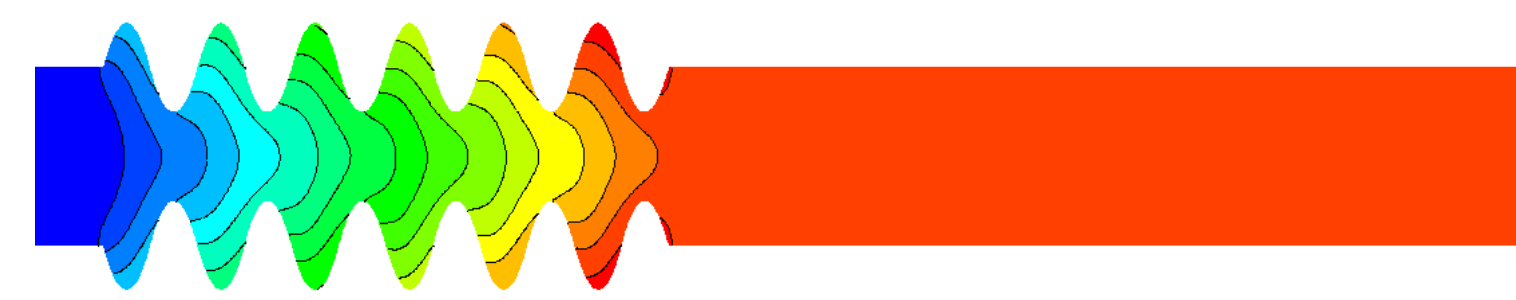

$\operatorname{Re}=10$

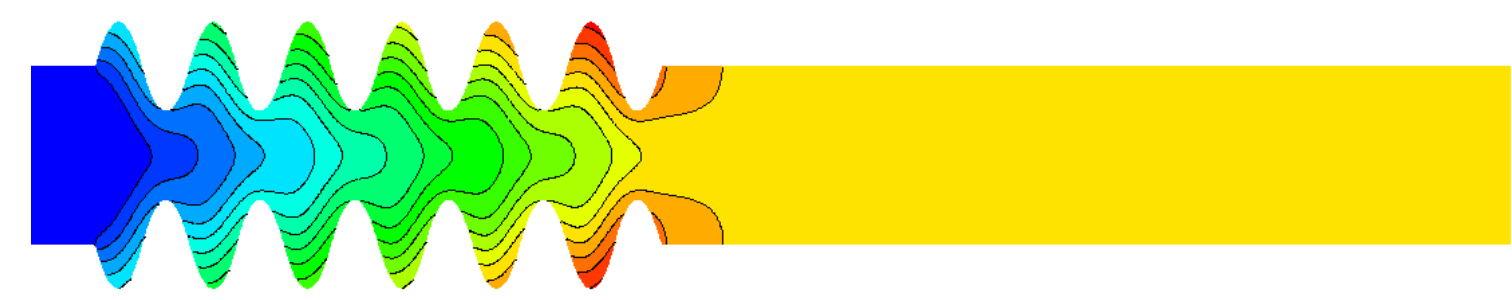

$\operatorname{Re}=20$

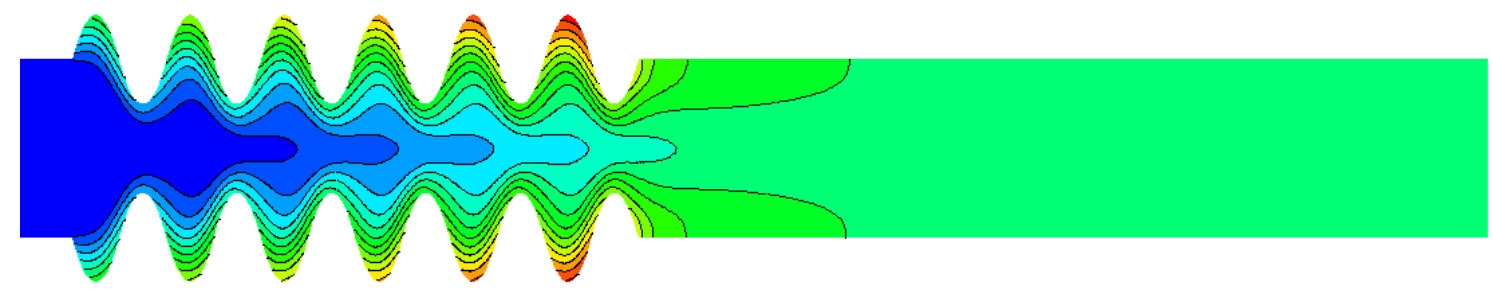

$\operatorname{Re}=100$

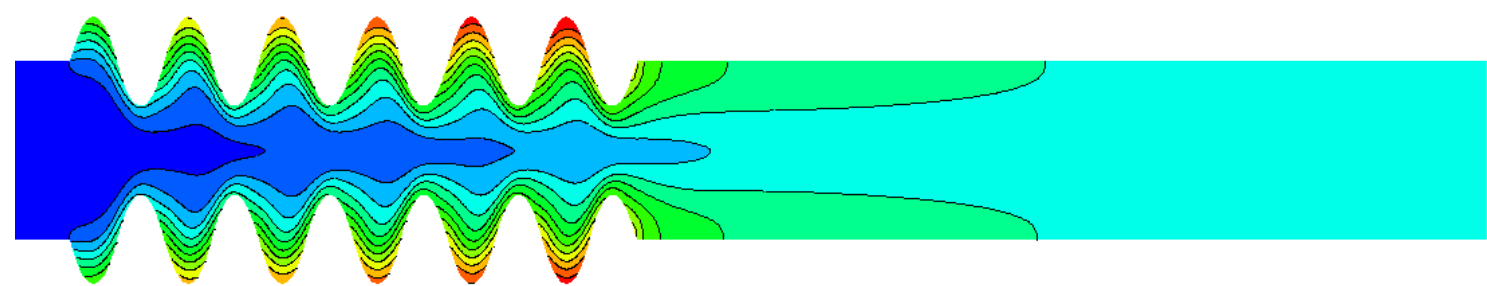

$\operatorname{Re}=200$

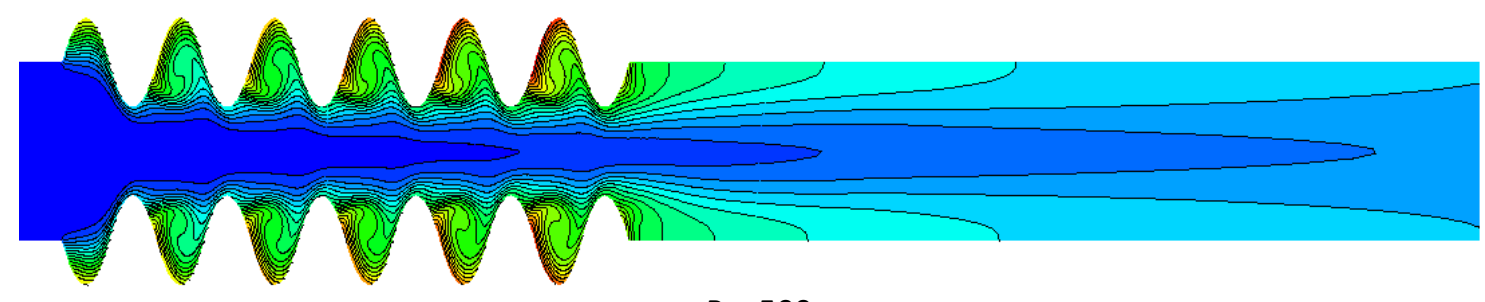

$\operatorname{Re}=500$

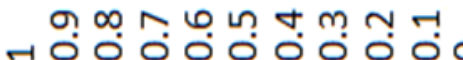

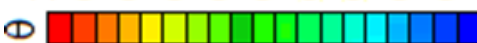

Fig. 6. Isothermal lines for values $\phi=0.03$ and different Reynolds numbers in the steady state

Figure 7 shows entropy lines in different states. It can be seen that with increasing Reynolds number, the amount of velocity increases and consequently the velocity gradient also enhances. On the other hand, with increasing speed, the temperature gradient increases, which increases the term related to the temperature gradient in the entropy equation, and therefore the generated entropy is determined by the following figures. As the Reynolds number increases, the entropy lines become 
denser. On the other hand, in channel indentations, due to the formation of vortices, entropy has increased in those areas, which can be seen in entropy lines.
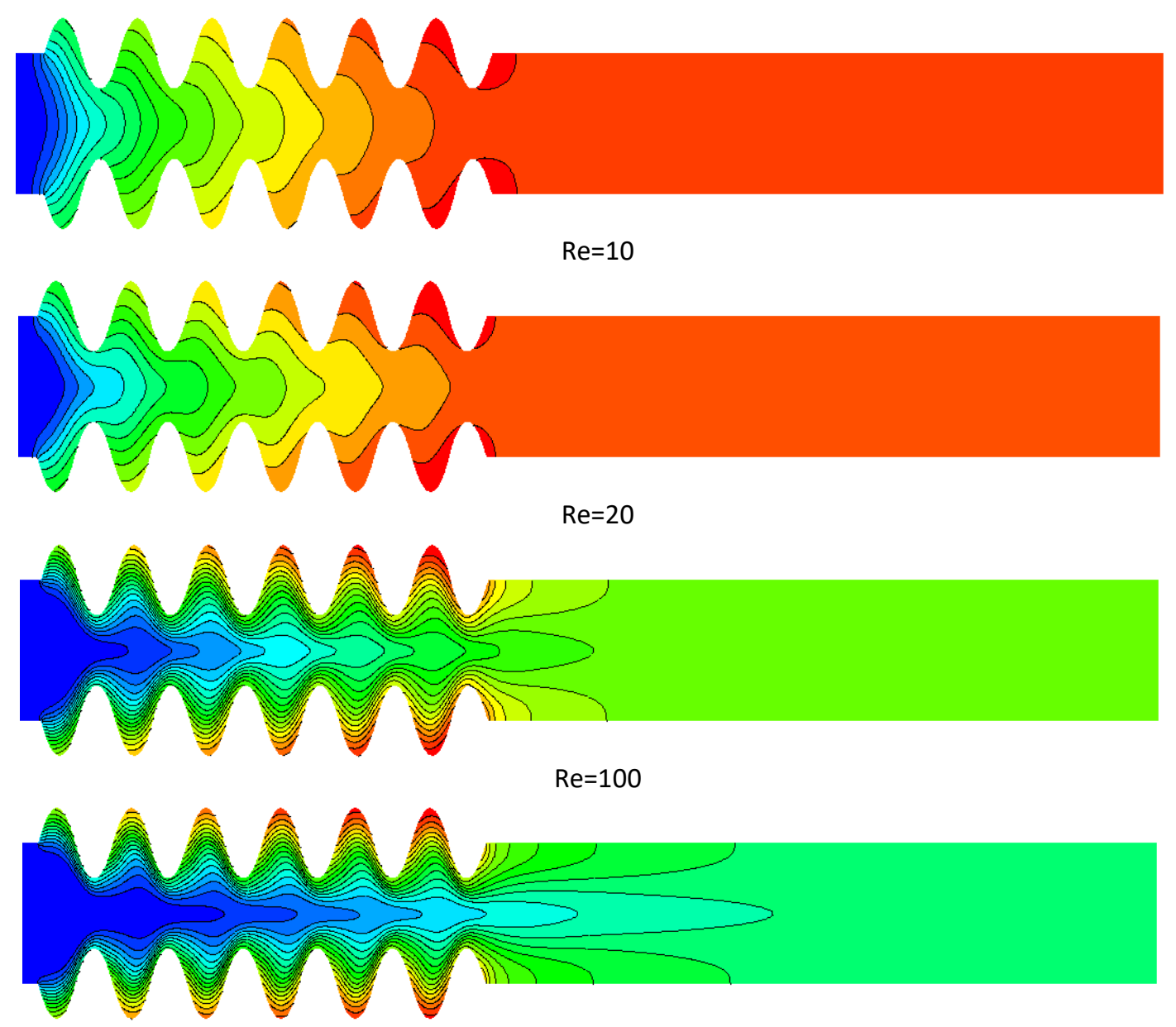

$\operatorname{Re}=200$
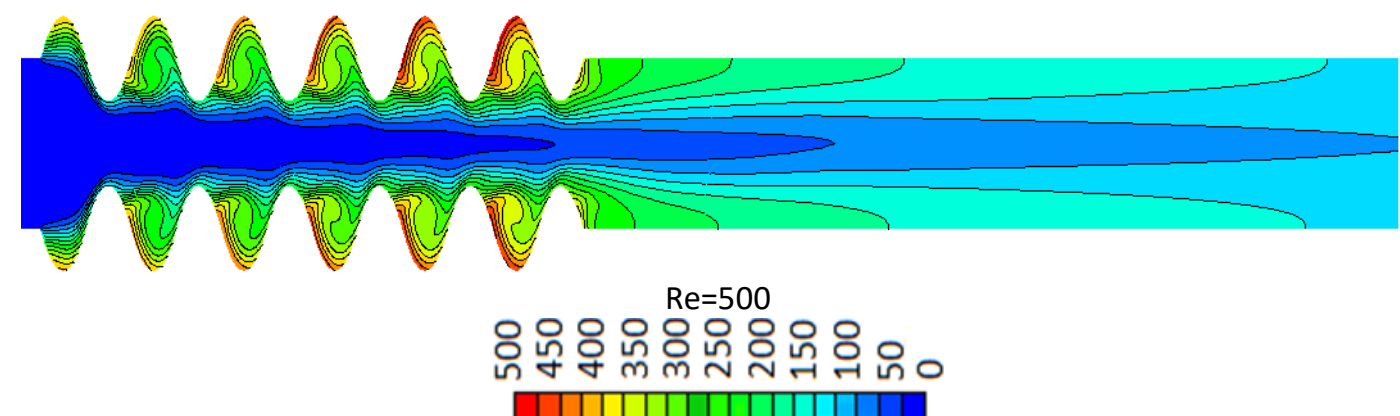

Fig. 7. Entropy lines for values $\phi=0.03$ and different Reynolds numbers in the steady state

Figure 8 shows the dimensional temperature changes on the central axis of the channel $(Y=0.5)$ for values $\phi=0.03$ and different Reynolds numbers. At the inlet section of the channel, it is observed that with increasing Reynolds due to increasing fluid velocity, the chance of temperature reaching the center of the channel from the lower wall is less and with increasing Reynolds number, the midline dimensionless temperature decreases. Reaching the wavy area due to the constant surface near the center of the channel, the temperature also increases. Passing through the last elevation also increases the temperature to the channel outlet by increasing the Reynolds number. This increase is lower in high Reynolds due to the predominant effects of current inertia. The results 
showed that in the length $L=20$ and central axis of the channel $(y=0.5)$, with decreasing Reynolds number, the temperature value increased sharply and reached from $\theta=0.1$ to $\theta=0.68$. This means that the temperature increases by $580 \%$.

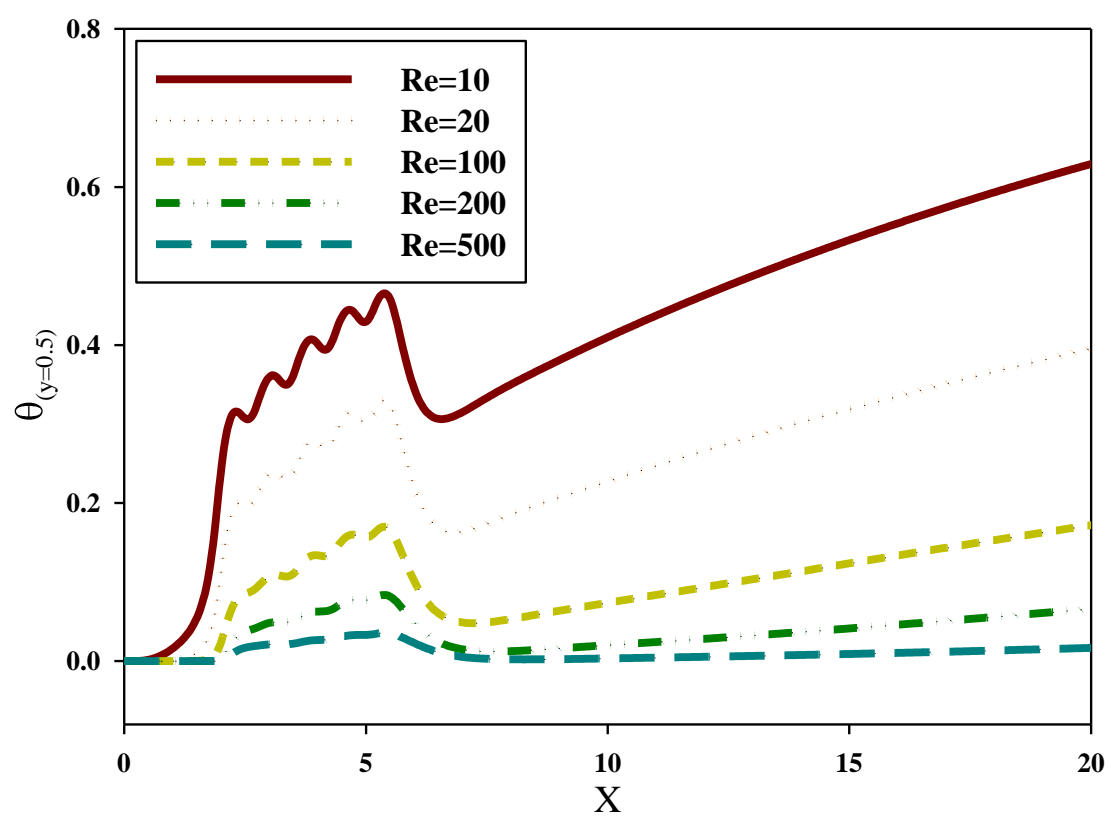

Fig. 8. Temperature on the midline of the channel for values $\phi=0.03$ and different Reynolds numbers

To better understand the effects of a wavy wall during forced convection, the maximum number of local Nusselt on the ridges is plotted in Figure 9.

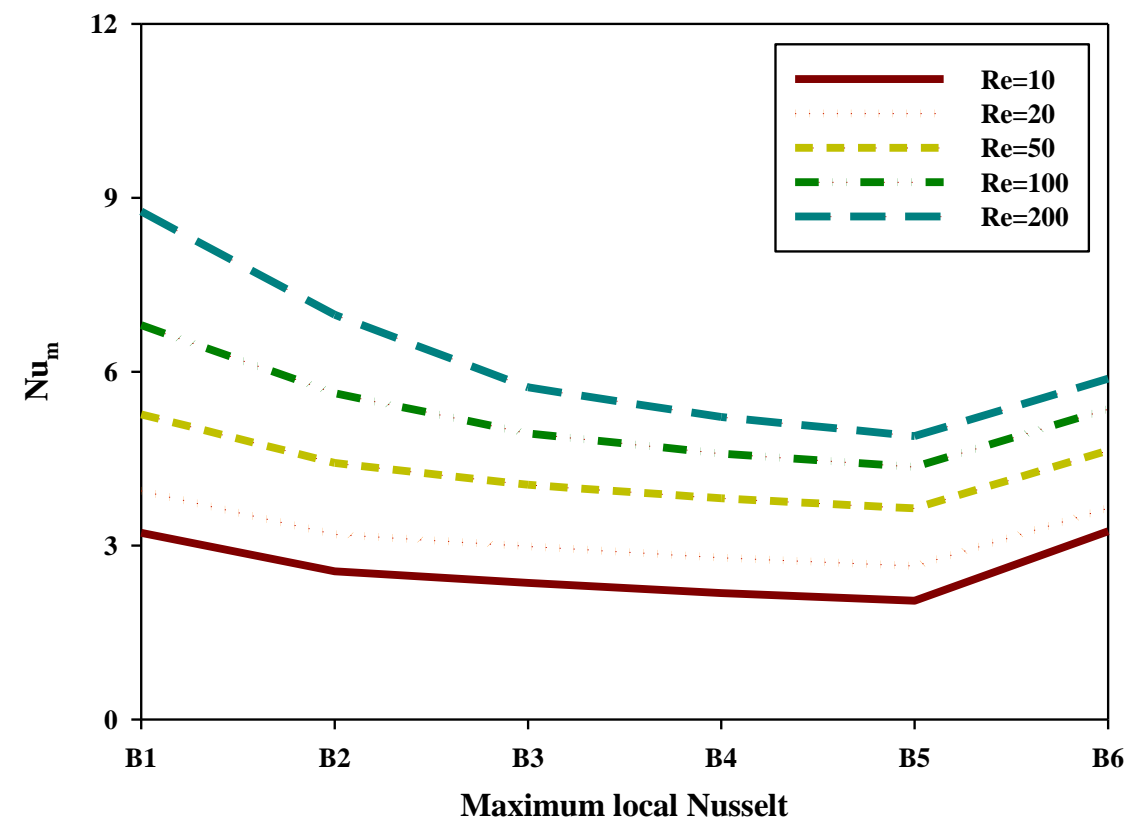

Fig. 9. The most localized Nusselt number on the tip of the ridges per values $\phi=0.03$ and Different Reynolds numbers 
The behavior was the same on all the ridges, but for example the Nusselt number increased on the last ridge. The results show that with increasing Reynolds number, the difference between surface temperature and adjacent fluid increases and as a result, Nusselt number increases. As we approach the end of the channel, the amount of heat absorption decreases due to the heating of the fluid, so the Nusselt number, which indicates the amount of heat transfer, decreases along the channel. But on the last ascent, the amount of Nusselt also increases due to the increase in speed. By increasing the Reynolds number from 10, 20, 50, 100 and 200, respectively, the value of the average Nusselt number in the lowest maximum local Nusselt B1 increases by $25 \%, 75 \%, 125 \%$ and $200 \%$ and In the highest maximum local Nusselt B6, the mean Nusselt number increases by $17 \%, 33 \%$, $64 \%$ and $93 \%$. By analyzing the changes in temperature and velocity (Figure 10 (a), (b)), it was found that with increasing time, the flow velocity towards a steady state is normal.

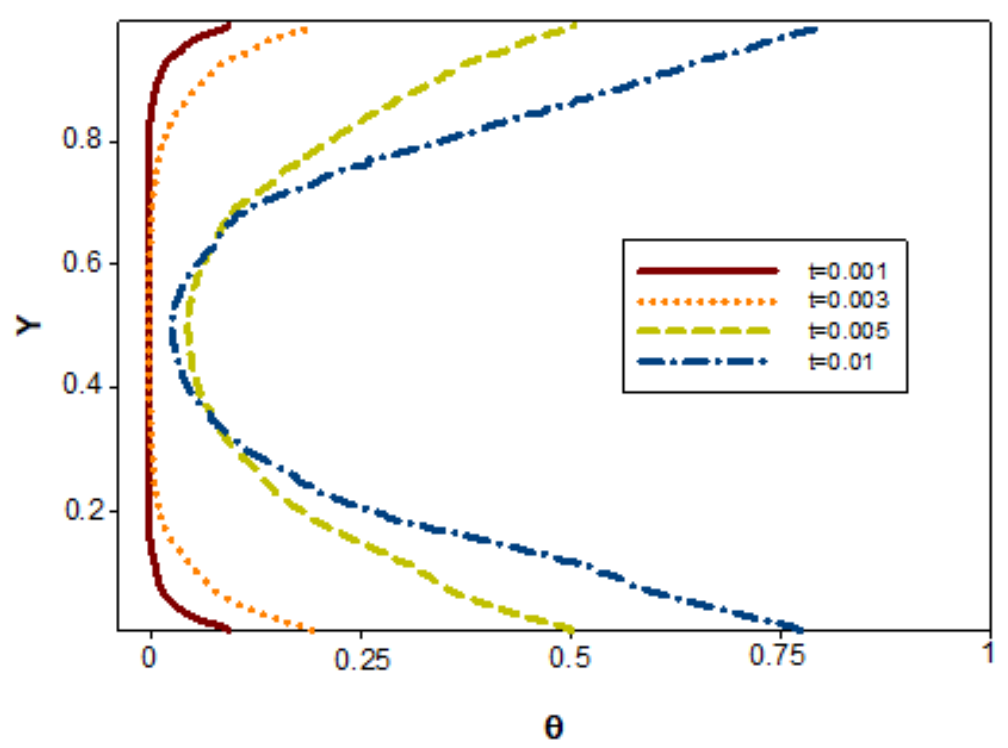

(a)

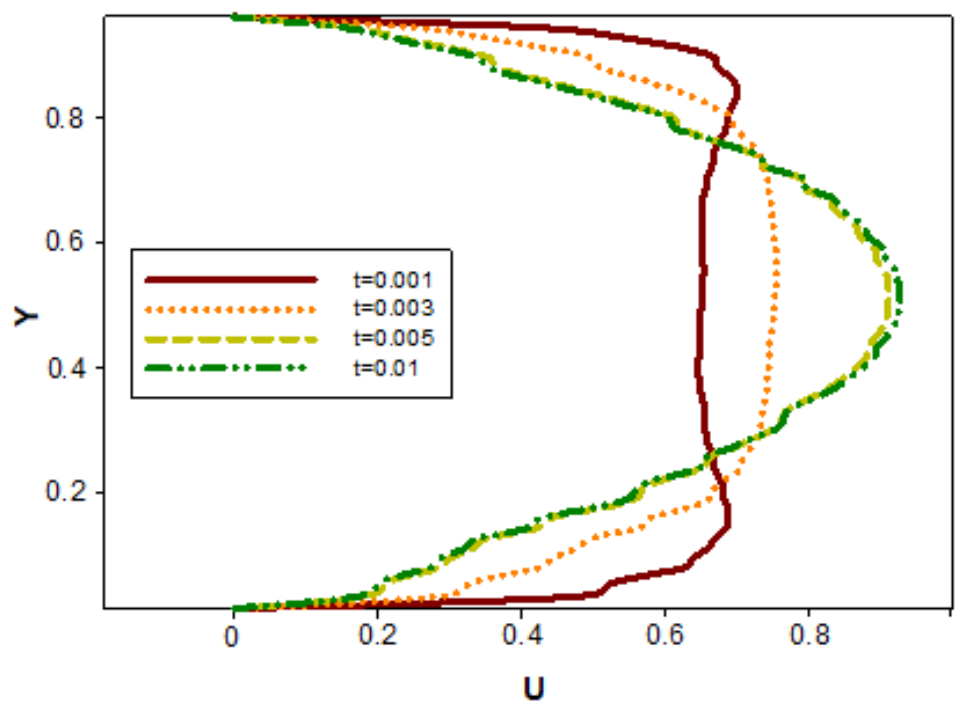

(b)

Fig. 10. (a) Temperature and (b) Speed changes at different times per $\mathrm{Re}=100$ and $\phi=0.03$ 
It was found that at the beginning of the flow, the temperature was penetrating the fluid and with increasing the penetration time, the wall temperature increased, which is well observed in the isothermal lines. Also, in the velocity profile, as seen in the flow lines, the velocity is higher near the walls and increases as the velocity near the wall increases.

\section{Conclusions}

In this study, the forced convection of a laminar flow of water-aluminium oxide nanofluid into a channel consisting of two parallel plates with a sinusoidal region is investigated. By numerically solving the governing equations, the effect of Reynolds number in steady and unsteady state was investigated. Also, due to the increase in the inertia of the flow, the inlet distance to the area where the flow is hydrodynamically developed increases. As the Reynolds number increases, the velocity also increases and the thickness of the boundary layer decreases, and the temperature gradient increases, and consequently the heat transfer rate increases. The total production entropy increases with increasing Reynolds number due to increasing velocity and increasing velocity and temperature gradient. In the unsteady mode, as the time increases, the current gradually moves away from the walls and the velocity in the centre of the channel increases. When the problem is in the unsteady state, the entropy increases with increasing time due to the infiltration of temperature into the centre of the channel and the increase of the temperature gradient and the predominance of the temperature gradient in the entropy equation.

\section{Acknowledgement}

Authors wish to thanks Universiti Teknologi Malaysia for supporting this research activity under Takasago grant (R.K130000.7343.4B472).

\section{References}

[1] Ewis, Karem Mahmoud. "Effects of Variable Thermal Conductivity and Grashof Number on Non-Darcian Natural Convection Flow of Viscoelastic Fluids with Non Linear Radiation and Dissipations." Journal of Advanced Research in Applied Sciences and Engineering Technology 22, no. 1 (2021): 69-80.

[2] Khan, Ansab Azam, Khairy Zaimi, Suliadi Firdaus Sufahani, and Mohammad Ferdows. "MHD Flow and Heat Transfer of Double Stratified Micropolar Fluid over a Vertical Permeable Shrinking/Stretching Sheet with Chemical Reaction and Heat Source." Journal of Advanced Research in Applied Sciences and Engineering Technology 21, no. 1 (2020): 1-14. https://doi.org/10.37934/araset.21.1.114

[3] Sahak, Ahmad Sofianuddin A., Nor Azwadi Che Sidik, and Siti Nurul Akmal Yusof. "Cubic Interpolation PseudoParticle Navier-Stokes Formulation Method for Solid Particle-Fluid Interaction in Channel Flow with Cavity." Journal of Advanced Research in Materials Science 70, no. 1 (2020): 1-17. https://doi.org/10.37934/arms.70.1.117

[4] Kerdarian, Majid, and Ehsan Kianpour. "Flow field, heat transfer and entropy generation of nanofluid in a microchannel using the finite volume method." Journal of Computational \& Applied Research in Mechanical Engineering (JCARME) 8, no. 2 (2019): 211-222.

[5] Idris, Muhammad Syafiq, Irnie Azlin Zakaria, and Wan Azmi Wan Hamzah. "Heat Transfer and Pressure Drop of Water Based Hybrid Al2O3: SiO2 Nanofluids in Cooling Plate of PEMFC." Journal of Advanced Research in Numerical Heat Transfer 4, no. 1 (2021): 1-13.

[6] Alvariño, P. Fariñas, JM Sáiz Jabardo, A. Arce, and MI Lamas Galdo. "A numerical investigation of laminar flow of a water/alumina nanofluid." International journal of heat and mass transfer 59 (2013): 423-432. https://doi.org/10.1016/i.ijheatmasstransfer.2012.12.033

[7] Ajeel, Raheem Kadhim, Wan Saiful-Islam Wan Salim, and Khalid Hasnan. "Impacts of corrugation profiles on the flow and heat transfer characteristics in trapezoidal corrugated channel using nanofluids." Journal of Advanced Research in Fluid Mechanics and Thermal Sciences 49, no. 2 (2018): 170-179.

[8] Rush, T. A., T. A. Newell, and A. M. Jacobi. "An experimental study of flow and heat transfer in sinusoidal wavy passages." International journal of heat and mass transfer 42, no. 9 (1999): 1541-1553. https://doi.org/10.1016/S0017-9310(98)00264-6 
[9] Yang, Liu, and Kai Du. "Numerical simulation of nanofluid flow and heat transfer in a microchannel: the effect of changing the injection layout arrangement." International Journal of Mechanical Sciences 172 (2020): 105415. https://doi.org/10.1016/i.ijmecsci.2019.105415

[10] Azman, Azraf, Mohd Zamri Yusoff, Azfarizal Mukhtar, Prem Gunnasegaran, Nasri A. Hamid, and Ng Khai Ching. "Numerical Study of Heat Transfer Enhancement for Mono and Hybrid Nanofluids Flow in a Straight Pipe." CFD Letters 13, no. 2 (2021): 49-61. https://doi.org/10.37934/cfdl.13.2.4961

[11] Naphon, Paisarn, and Kirati Kornkumjayrit. "Numerical analysis on the fluid flow and heat transfer in the channel with V-shaped wavy lower plate." International Communications in Heat and Mass Transfer 35, no. 7 (2008): 839843. https://doi.org/10.1016/i.icheatmasstransfer.2006.09.003

[12] Pehlivan, Hüseyin, I. Taymaz, and Yaşar İslamoğlu. "Experimental study of forced convective heat transfer in a different arranged corrugated channel." International Communications in Heat and Mass Transfer 46 (2013): 106111. https://doi.org/10.1016/i.icheatmasstransfer.2013.05.016

[13] Akbarzadeh, M., Saman Rashidi, and J. A. Esfahani. "Influences of corrugation profiles on entropy generation, heat transfer, pressure drop, and performance in a wavy channel." Applied Thermal Engineering 116 (2017): $278-291$. https://doi.org/10.1016/i.applthermaleng.2017.01.076

[14] Muhammad, Nura Mu'az, Nor Azwadi Che Sidik, Aminuddin Saat, and Bala Abdullahi. "Effect of nanofluids on heat transfer and pressure drop characteristics of diverging-converging minichannel heat sink." CFD Letters 11, no. 4 (2019): 105-120.

[15] Muhammad, Nura Mu'az, and Nor Azwadi Che Sidik. "Utilisation of nanofluids in minichannel for heat transfer and fluid flow augmentation." J. Adv. Res. Design 51, no. 1 (2018): 18-45.

[16] Beng, Soo Weng, and Wan Mohd Arif Aziz Japar. "Numerical analysis of heat and fluid flow in microchannel heat sink with triangular cavities." Journal of Advanced research in fluid mechanics and thermal sciences 34 (2017): 1-8.

[17] Xie, Gongnan, Zhiyong Chen, Bengt Sunden, and Weihong Zhang. "Comparative study of the flow and thermal performance of liquid-cooling parallel-flow and counter-flow double-layer wavy microchannel heat sinks." Numerical Heat Transfer, Part A: Applications 64, no. 1 (2013): 30-55. https://doi.org/10.1080/10407782.2013.773811

[18] Zhang, Yan, Bo Yuan, Yu Bai, Yingjian Cao, and Yunpeng Shen. "Unsteady Cattaneo-Christov double diffusion of Oldroyd-B fluid thin film with relaxation-retardation viscous dissipation and relaxation chemical reaction." Powder Technology 338 (2018): 975-982. https://doi.org/10.1016/i.powtec.2018.07.049

[19] Ajeel, Raheem Kadhim, Wan Saiful-Islam Wan Salim, and Khalid Hasnan. "Heat transfer enhancement in semicircle corrugated channel: effect of geometrical parameters and nanofluid." Journal of Advanced Research in Fluid Mechanics and Thermal Sciences 53, no. 1 (2019): 82-94.

[20] Han, Huaizhi, Bingxi Li, and Wei Shao. "Multi-objective optimization of outward convex corrugated tubes using response surface methodology." Applied thermal engineering 70, no. 1 (2014): $250-262$. https://doi.org/10.1016/j.applthermaleng.2014.05.016

[21] Do, Kyu Hyung, and Seok Pil Jang. "Effect of nanofluids on the thermal performance of a flat micro heat pipe with a rectangular grooved wick." International Journal of Heat and Mass Transfer 53, no. 9-10 (2010): $2183-2192$. https://doi.org/10.1016/j.ijheatmasstransfer.2009.12.020

[22] Asadi, Amin, Ibrahim M. Alarifi, Vakkar Ali, and Hoang M. Nguyen. "An experimental investigation on the effects of ultrasonication time on stability and thermal conductivity of MWCNT-water nanofluid: Finding the optimum $\begin{array}{llll}\text { ultrasonication } \quad \text { time." Ultrasonics } & \text { sonochemistry } 58 & \text { (2019): } 104639 .\end{array}$ https://doi.org/10.1016/i.ijnonlinmec.2011.07.013

[23] Shahsavar, Amin, Seyed Saman Alimohammadi, Ighball Baniasad Askari, and Hafiz Muhammad Ali. "Numerical investigation of the effect of corrugation profile on the hydrothermal characteristics and entropy generation behavior of laminar forced convection of non-Newtonian water/CMC-CuO nanofluid flow inside a wavy channel." International Communications in Heat and Mass Transfer 121 (2021): 105117. https://doi.org/10.1016/j.icheatmasstransfer.2021.105117

[24] Aminossadati, S. M., A. Raisi, and B. Ghasemi. "Effects of magnetic field on nanofluid forced convection in a partially heated microchannel." International Journal of Non-Linear Mechanics 46, no. 10 (2011): 1373-1382. https://doi.org/10.1016/j.ijnonlinmec.2011.07.013

[25] Karniadakis, George, Ali Beskok, and Narayan Aluru. Microflows and nanoflows: fundamentals and simulation. Vol. 29. Springer Science \& Business Media, 2006.

[26] Xuan, Yimin, and Wilfried Roetzel. "Conceptions for heat transfer correlation of nanofluids." International Journal of heat and Mass transfer 43, no. 19 (2000): 3701-3707. https://doi.org/10.1016/S0017-9310(99)00369-5

[27] Vajjha, Ravikanth S., and Debendra K. Das. "Experimental determination of thermal conductivity of three nanofluids and development of new correlations." International Journal of Heat and Mass Transfer 52, no. 21-22 (2009): 46754682. https://doi.org/10.1016/i.ijheatmasstransfer.2009.06.027 
[28] Koo, Junemoo, and Clement Kleinstreuer. "Laminar nanofluid flow in microheat-sinks." International journal of heat and mass transfer 48, no. 13 (2005): 2652-2661. https://doi.org/10.1016/j.ijheatmasstransfer.2005.01.029

[29] Prakash, A., S. Satsangi, S. Mittal, B. Nigam, P. K. Mahto, and Bibhu P. Swain. "Investigation on Al2O3 nanoparticles for nanofluid applications-a review." In IOP conference series: materials science and engineering, vol. 377, no. $1, \mathrm{p}$. 012175. IOP Publishing, 2018. https://doi.org/10.1088/1757-899X/377/1/012175

[30] Patankar, Suhas V. "Numerical heat transfer and fluid flow". CRC press, (2018). https://doi.org/10.1201/9781482234213

[31] Alonzo-García, Alejandro, Claudia del Carmen Gutiérrez-Torres, and José Alfredo Jiménez-Bernal. "Computational Fluid Dynamics in Turbulent Flow Applications. From Brain Imaging to Turbulent Flows, (2016). https://doi.org/10.5772/63831

[32] Aminossadati, S. M., and B. Ghasemi. "Natural convection cooling of a localised heat source at the bottom of a nanofluid-filled enclosure." European Journal of Mechanics-B/Fluids 28, no. 5 (2009): 630-640. https://doi.org/10.1016/i.euromechflu.2009.05.006

[33] Sidik, Nor Azwadi Che, Maysam Khakbaz, Leila Jahanshaloo, Syahrullail Samion, and Amer Nordin Darus. "Simulation of forced convection in a channel with nanofluid by the lattice Boltzmann method." Nanoscale research letters 8, no. 1 (2013): 1-8. https://doi.org/10.1186/1556-276X-8-178 